\title{
Sex-Linked Hereditary Bilateral Anophthalmos
}

\section{Citation}

Brunquell, Philip J., John H. Papale, Jonathan C. Horton, Roger S. Williams, Michael J. Zgrabik, Daniel M. Albert, and E. Tessa Hedley-Whyte. "Sex-linked hereditary bilateral anophthalmos: pathologic and radiologic correlation." Archives of Ophthalmology 102, no. 1 (1984): 108-113.

\section{Published Version}

10.1001/archopht.1984.01040030092044

\section{Permanent link}

http://nrs.harvard.edu/urn-3:HUL.InstRepos:32439625

\section{Terms of Use}

This article was downloaded from Harvard University's DASH repository, and is made available under the terms and conditions applicable to Other Posted Material, as set forth at http:// nrs.harvard.edu/urn-3:HUL.InstRepos:dash.current.terms-of-use\#LAA

\section{Share Your Story}

The Harvard community has made this article openly available.

Please share how this access benefits you. Submit a story.

Accessibility 


\title{
Sex-Linked Hereditary Bilateral Anophthalmos
}

\author{
Pathologic and Radiologic Correlation
}

\author{
Philip J. Brunquell, MD; John H. Papale, MD; Jonathan C. Horton, PhD; Roger S. Williams, MD; \\ Michael J. Zgrabik, MD; Daniel M. Albert, MD; E. Tessa Hedley-Whyte, MD
}

\begin{abstract}
- A 27-year-old man had X-linked true anophthalmos. No evidence of optic globe, nerves, or chiasm was found. Rudimentary structures suggesting optic tracts were present. Lateral geniculate nuclei were present but gliotic. Calcarine cortex was thinner but had usual lamination. The normal patches of cytochrome oxidase activity in layers II and III of visual cortex were absent.
\end{abstract}

(Arch Ophthaimol 1984;102:108-113)

$\mathrm{T}_{\mathrm{e}}^{\mathrm{r}}$ rue anophthalmos is a rare clinical entity, and the diagnosis can only be made by histologic examination of the orbital contents. Cases with pathologic substantiation of both the intraorbital and the intracranial components of the visual system are still rare. $^{[\cdot 3}$ We present herein the radiologic and postmortem follow-up in a case of an X-linked recessive form of anophthalmos originally reported by Hoefnagel et al. ${ }^{4}$ In addition to serial sections of both orbital contents, the

\section{Accepted for publication Jan 5, 1983}

From the Charles S. Kubik Laboratory for Neuropathology, Massachusetts General Hospital (Drs Brunquell, Williams, and HedleyWhyte); Howe Laboratory, Massachusetts Eye and Ear Infirmary (Drs Papale, Zgrabik, and Albert); and the Departments of Neurology (Drs Brunquell and Williams), Ophthalmology (Drs Papale and Zgrabik), Neurobiology (Dr Horton) and Pathology (Dr Hedley-Whyte), Harvard Medical School, Boston.

Presented in part at the American Academy of Neurology meeting, San Diego, April 30, 1983.

Reprint requests to Department of Pathology, Massachusetts General Hospital, Boston, MA 02114 (Dr Hedley-Whyte). left lateral geniculate nucleus, and the left calcarine cortex, the functional state of the right visual cortex was investigated with the use of the cytochrome oxidase reaction. ${ }^{5}$

\section{REPORT OF A CASE}

The report that follows is a brief summary. For additional details, see the report of Hoefnagel et al. ${ }^{4}$

The patient was born (weighing $2.7 \mathrm{~kg}$ at term) to a 26 -year-old mother (gravida 3 , para 2). Parents were nonconsanguineous and of normal intelligence. The pedigree of the family updated from the previous report includes another maternal male cousin with unilateral anophthalmia and contralateral microphthalmia and is shown in Fig 1.

The patient had clubbed feet, small head, and no eyes. He sat at 1 year, stood with assistance at 5 years, and was never able to stand or walk independently. His first words were uttered at 3 to 4 years.

At the age of $7^{1 / 2}$ years, his head circumference was $49 \mathrm{~cm}$ (second percentile). His ears were large and outstanding. The eyeballs were absent, but eyelids, cilia, eyebrows, lacrimal puncta, and tarsal cartilages were present. Epicanthal folds were noted bilaterally, and palpebral fissures were $20 \mathrm{~mm}$ in width. Conjunctival membranes of normal appearance lined the orbital cavities, which were $15 \mathrm{~mm}$ in their greatest depth. Vigorous lid-closure followed touching the membranes. The lacrimal glands were enlarged, and tearing was normal. There was reactive blinking to touch and loud noise. Cranial nerves other than II, III, IV, and VI were normal. Muscle tone was normal; bulk was diffusely diminished. Sensation to noxious stimuli was intact. Muscle stretch reflexes were $1+$ bilaterally with flexor plantar responses. The right testis was undescended. Karyo- type was normal. An EEG showed absence of a posterior $\alpha$-rhythm and no driving response to photic stimulation. Skull x-ray films were normal, except for showing shallow orbits and small optic foramina.

At the age of $11^{1 / 2}$ years, he was admitted to a state institution, at which time height, weight, and head circumference were all less than the second percentile.

When he was 15 years old, a grand mal seizure lasting five minutes was witnessed for the first time. His CSF was normal. An EEG showed, in addition to absent $\alpha$-rhythm, generalized low-voltage fast activity and intermittent bilateral sharp waves, most prominent posteriorly. Seizures were controlled with phenobarbital and phenytoin (Dilantin). An examination when the patient was 16 years old showed spastic paraparesis, flexion contractures, and a severe scoliosis.

When he was 25 years old, computed tomography (CT) showed densities within the orbits having the appearance of rudimentary extraocular muscles. Ovoid lucencies anteriorly in both orbits were believed to be rudimentary eye tissue (Fig 2). Optic foramina were present bilaterally. The ventricles were slightly enlarged, and cranial asymmetry was noted. Large accessory bony sinuses were present in the frontal regions (Fig 3).

After an episode of hypothermia at the age of $26 \frac{1}{2}$ years, he was found to have a low thyroxine level $(3.7 \mu \mathrm{g} / \mathrm{dL})$ and an elevated thyrotropin level $(14 \mu \mathrm{U} / \mathrm{mL})$ and was begun on levothyroxine sodium (Synthroid) therapy. At the age of 26 years, hydrocortisone therapy was started for hypoadrenalism.

He died of aspiration pneumonia at the age of 27 years.

\section{PATHOLOGIC FINDINGS}

Postmortem examination revealed 


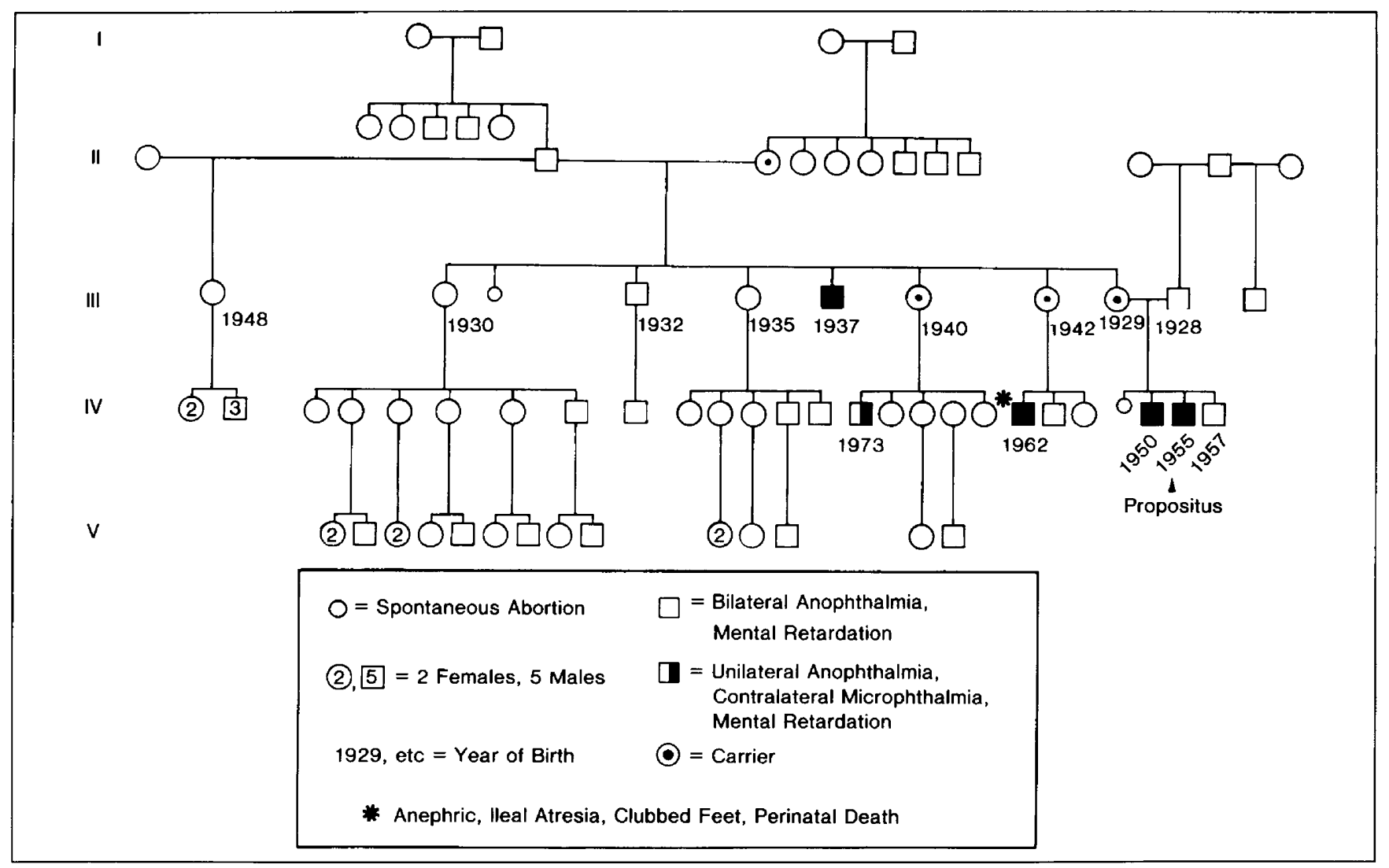

Fig 1. - Pedigree of family updated from Hoefnagel et al. ${ }^{4}$

bilateral bronchopneumonia, kyphoscoliosis, muscular wasting, bilateral cryptorchidism, and atrophy of the thyroid, adrenal glands, and testes.

The calvarium was asymmetric, with a right parietal protuberance. Head circumference was $54 \mathrm{~cm}$, with thickened cranial sutures. Large accessory bony sinus cavities superior to the orbital contents did not communicate with the frontal sinuses (Fig 3 ). The pituitary fossa was small, with marked thickening of the anterior and posterior clinoids and the petroclinoid dura.

The orbits were unroofed through the accessory frontal sinuses and contained no identifiable eye tissue. The extraocular muscles were in their normal positions. The anterior portion of the orbital contents in the left eye contained a firm nubbin of connective tissue. Tissue removed from the orbital cavities measured $40 \mathrm{~mm}$ in length, $27 \mathrm{~mm}$ in width, and $30 \mathrm{~mm}$ vertically on the right, and $70 \mathrm{~mm}$ in length, 35 $\mathrm{mm}$ in width, and $23 \mathrm{~mm}$ vertically on the left.

Step sections of both orbital contents revealed similar constituents, including peripheral nerve, autonomic ganglion cells, connective tissue, striated muscle, blood vessels, fat, nonkeratinized stratified epithelium, areas of mild chronic nongranulomatous inflammation, and lacrimal glands (Fig 2). There was pigment along some nerve fibers. No trace of cornea, lens, uveal tissue, retina, pigment epithelium, or optic nerve was found.

The brain weighed $1,050 \mathrm{~g}$. Optic nerves and chiasm were absent (Fig 4). The third and sixth cranial nerves were present but smaller than normal. The frontal lobes were particularly small. All primary gyri and sulci were identified, although the calcarine fissures were shorter than normal (Fig 5).

Although medial geniculate nuclei were well defined in coronal section, lateral geniculate nuclei and optic tracts were not grossly visible. The subcortical white matter of the cerebral hemispheres was diffusely firm, and the ventricles were slightly dilated. The brain stem, cerebellum, spinal cord, and blood vessels were normal.

The sites of the optic tracts were visible microscopically, more apparent on the left than the right, as small gliotic structures without myelinated fibers. The lateral geniculate bodies occupied their normal position (Fig 6) but were small, measuring $0.3 \times 0.2$ $\mathrm{mm}$, with an anteroposterior extent of only $2.5 \mathrm{~mm}$. The nucleus was severely gliotic, with a few, both small and large, neurons, but normal lamination was completely lacking (Fig 6). The optic radiations were much thinner than normal.

In serial sections through the left calcarine cortex, primary visual cortex (area 17) could be clearly identified by the boundary between areas 17 and 18 (Fig 7). The basic layering pattern of area 17 was preserved, although several anomalies were noted. Area 17 seemed less richly laminated than usual. Layer IVb was not visible as the usually cell-poor gap between IVc and the supragranular layers. Myelin stains confirmed the absence of a well-myelinated line of Gennari. Finally, with the use of Nissl's staining method, the density and size of cells seemed generally reduced throughout striate cortex. Superior colliculi appeared normal in cell stains, but the myelinated fiber bundles of the stratum opticum, the retinocollicular afferents in the normal brain, were absent.

In specimens of normal human striate cortex, regular patches of enhanced cytochrome oxidase activity are visible, particularly in layers II and III $^{5}$ (Fig 8). In this case of anophthalmia, no cytochrome oxidase 


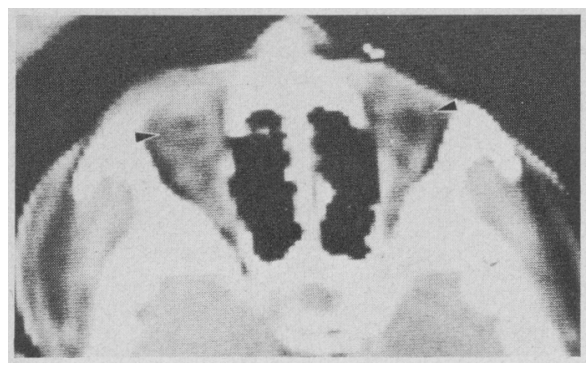

Fig 2.-Left, Axial section through orbits showing ovoid areas of low density (arrowheads) surrounded by tissue of medium density suggesting presence of globes. Right, Histologic section of right orbital contents shows central coalescence of fat surrounded by muscle $(M)$, peripheral nerve $(N)$, and lacrimal gland $(L)$. Eye tissue is conspicuously absent (trichrome, $\times 2.5$ ).

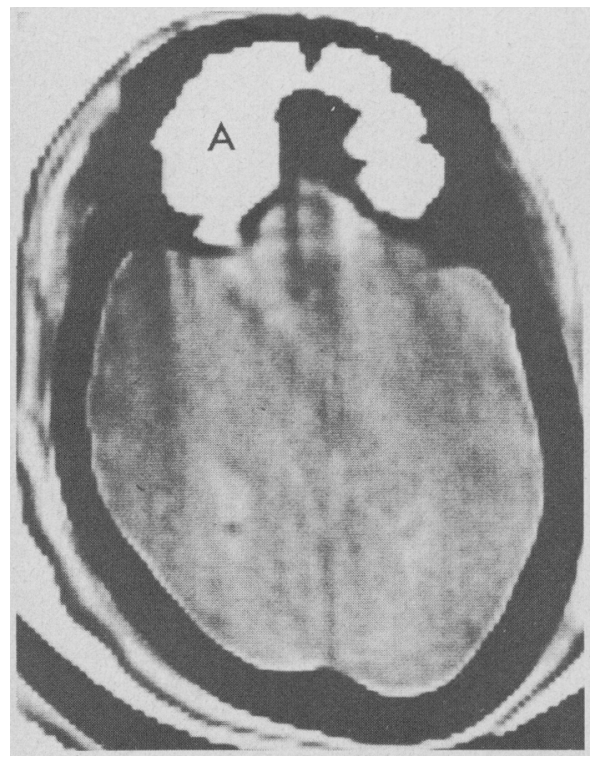

patches were present, as shown in Fig 8 , a tangential section through layers II and III. In addition, the thick band of dark enzyme staining usually present in layer IVc was very weak.

The small neurons of neocortical layer IV appeared diminished in number in inferior frontal and temporal areas. The inferior olives were gliotic, with marked decrease in cell numbers, increased numbers of astrocytes, and diminution of myelinated fibers in the hilum. The cerebellum showed diffuse decrease of granule cells and Purkinje's cells. There were numerous spheroids in the cuneate nuclei bilaterally without demyelination in the posterior cord.
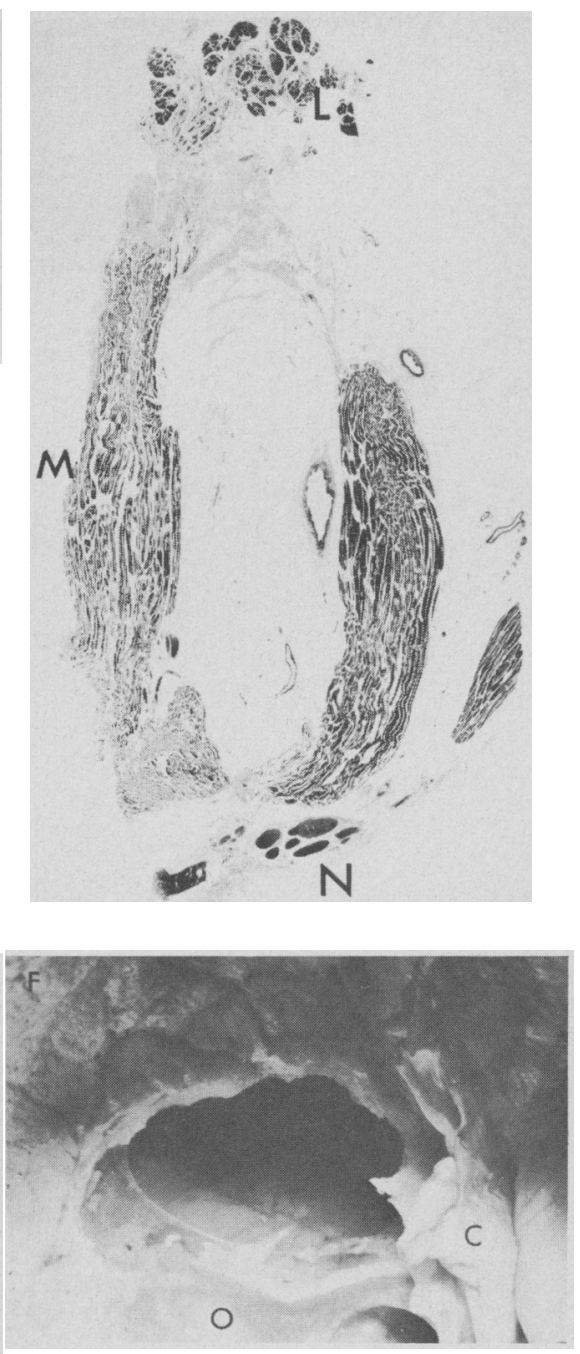

Fig 3.-Left, Axial section revealing large accessory sinuses (A) in frontal bone. Right, Enlarged left frontal sinus partially overlying orbit. Note orbital roof $(\mathrm{O})$, crista galli $(\mathrm{C})$, and frontal bone $(F)$.

\section{COMMENT}

Although Lycosthenes referred to anophthalmos in 1557,6 it was not until a century later that Bartholin provided the first medical description. ${ }^{7}$ Briggs, ${ }^{8}$ in the early 19 th century, called attention to the possible familial occurrence of the disease. The first large clinical series, albeit without histologic verification, was by Treacher-Collins in 1887. ${ }^{9}$ Numerous reports followed, with little attempt to delineate the precise nature of any intraorbital tissue until Mann ${ }^{10}$ subdivided this heterogeneous group into three distinct entities: primary anophthalmos resulting from failure

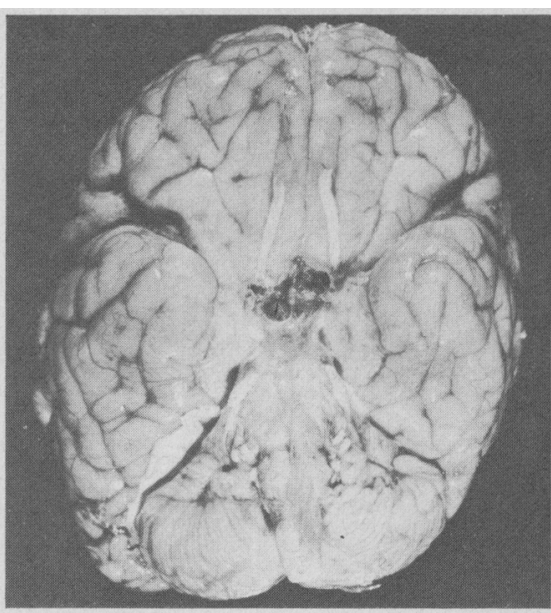

Fig 4.-Inferior surface of brain showing absence of optic nerves and chiasm. Third and sixth cranial nerves are present.

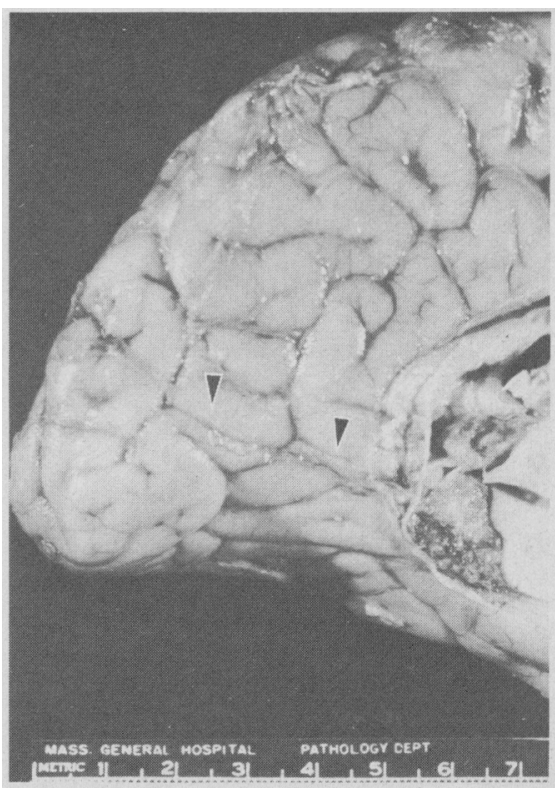

Fig 5.-Posteromedial surface of cerebral hemisphere showing shortened calcarine fissure (arrowheads) that does not reach occipital pole. Primary gyri and sulci are otherwise normal.

of development of the optic vesicles; secondary anophthalmos, where failure of eye formation occurs as a component of more generalized abnormal forebrain development; and degenerative or consecutive anophthalmos due to complete regression or involution of a previously formed optic vesicle. In all cases there is virtual absence of any neuroectodermal derivatives within the orbit. When such derivatives are present in a patient with no grossly evident eye structures, extreme microphthalmos is a more appropriate designation. Despite the apparent ease of this classification, it offers little insight into pathogenesis, since cases with no residual eye tissue 


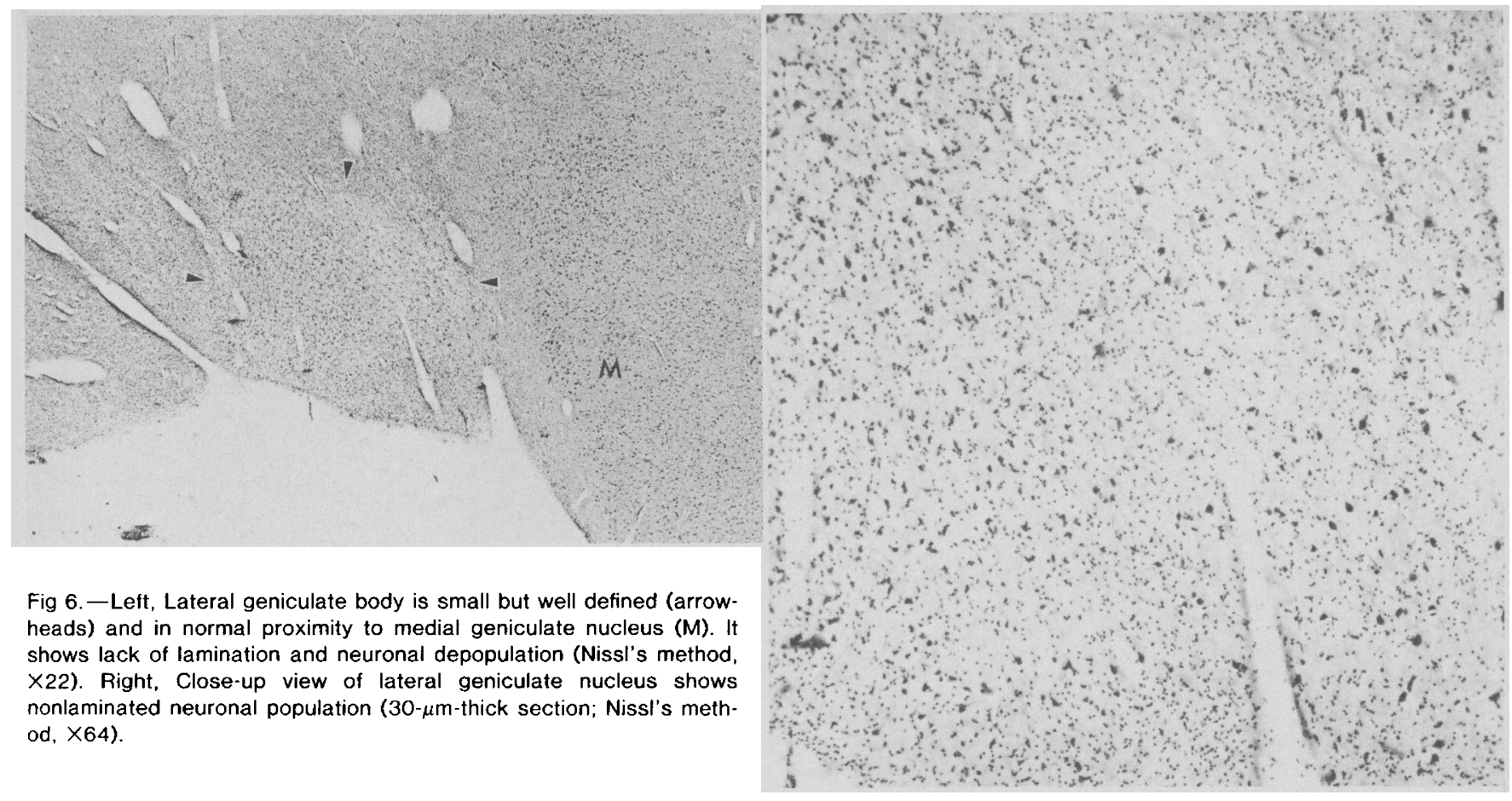

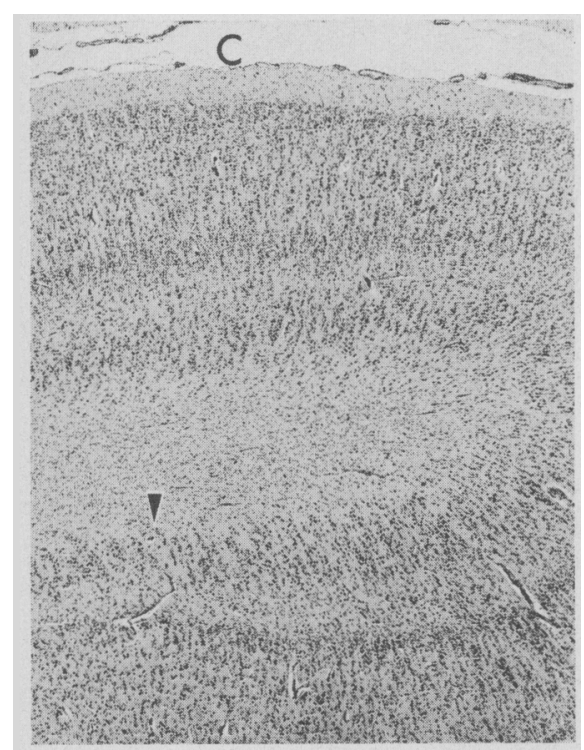

Fig 7. - Calcarine fissure (C) with striate cortex above and junction between areas 17 and 18 below (arrowhead). Note well-laminated striate cortex with thinner than usual layer IVb (20- $\mu \mathrm{m}$-thick section; Nissl's method, $\times 26$ ).

may not always be ascribable to agenesis or degeneration. Furthermore, extrapolation to experimental models is limited as these are not characterized by complete failure of optic cup evagination.

In 1963, Duke-Elder ${ }^{11}$ acknowledged the difficulty in distinguishing the nature of orbital contents on clinical grounds alone and pointed out that the true form of anophthalmos was rare and that most cases showed some

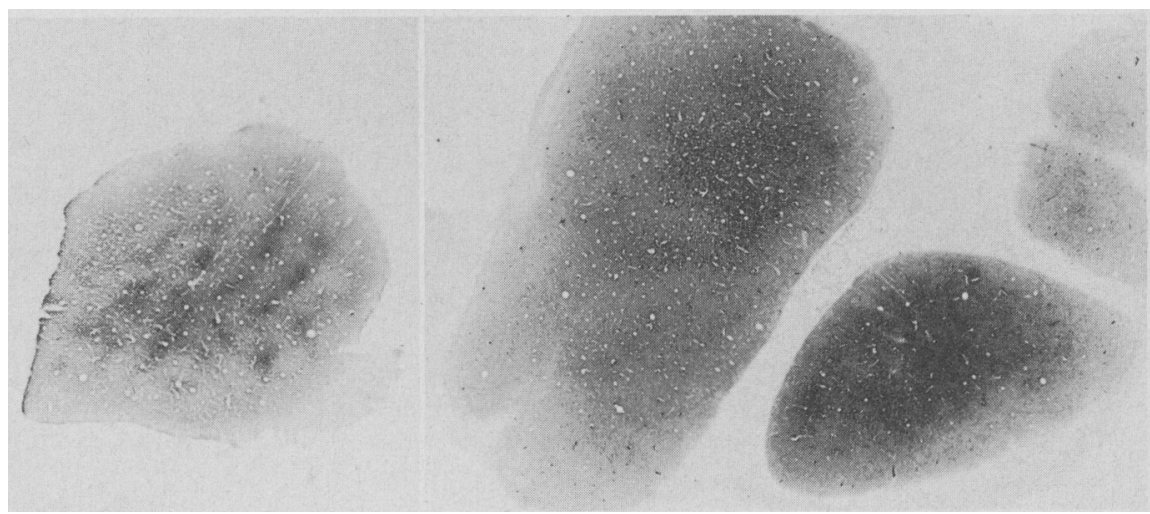

Fig 8. - Left, Tangential section through superficial layers I, II, and III of normal visual cortex stained for cytochrome oxidase activity showing regular patches of cytochrome oxidase activity $(\times 10)$. Right, Comparable section of patient's visual cortex showing uniform distribution of cytochrome oxidase activity with no patches $(\times 10)$.

intraorbital representation of neuroectodermal structures. This observation is strengthened by the fact that only 13 cases of primary anophthalmos had been tabulated as of $1980 .^{12}$ Newer noninvasive techniques, such as orbital ultrasound ${ }^{13}$ and CT scan, may suggest a premortem diagnosis but must be interpreted with caution. In this case, for instance, the central collection of orbital fat (low absorption) surrounded by muscle, peripheral nerves, and connective tissue (medium absorption) suggested the presence of globes.

The heredity of familial anophthalmos is heterogeneous. Most cases are distributed in an autosomal recessive pattern, ${ }^{14-18}$ but a dominant pattern has also been reported.19 However, when anophthalmia is associated with mental retardation and/or multiple congenital malformations, case distribution is more consistent with a sexlinked recessive pattern of inheritance. ${ }^{17-22}$ A nophthalmos has also been associated with drugs, ${ }^{23-25}$ congenital infection, ${ }^{26}$ vitamin $\mathrm{A}$ deficiency, ${ }^{27}$ mechanical trauma to the fetus, ${ }^{28}$ chromosomal aberrations, ${ }^{29.33}$ and idiopathic multiple malformation syndromes. ${ }^{34-36}$ Animal models exist for many of these ${ }^{37}$ and also suggest a few others, such as radiation ${ }^{38}$ and altered immunity. ${ }^{39}$ The association of anophthalmos with parasellar mass lesions suggests that local pressure may destroy the developing visual system. ${ }^{1,40.41}$

Typically, as in this patient, the structures that are not derived from neuroectoderm are present, that is, 
the eyelids, cilia, lacrimal apparatus, conjunctival lining, and extraocular muscles. The absence of the lens seems to be due to the failure of the optic cup to make proper contact with the lens placode ${ }^{37}$ suggesting that the critical period is the development of the optic vesicle and cup. This has been demonstrated in the mutant anophthalmic mouse ZRDCT/An, which serves as a suitable animal model for the human disorder. ${ }^{42.43}$ The conformation of the optic cup may also be a critical factor in determining the ultimate presence or absence of eyes. ${ }^{43}$ The mutant mouse (ZRDCT/ Ch) initially develops optic vesicles, which induce a small and poorly oriented lens that cannot be assimilated into the optic cup, and ultimately both degenerate. The small orbits in our case seem to be a result of the failure of normal eye development. ${ }^{44}$

In the anophthalmic mouse, the dorsal lateral geniculate nucleus shows a loss of both neurons and glia and a failure to develop a laminar pattern. ${ }^{45}$ These changes are more severe in the mice enucleated postnatally than in the anophthalmic mice. The degree of gliosis in the lateral geniculate nucleus and the apparent remnants of optic tracts in our patient suggest that the optic cup development had proceeded to the retinogeniculate interaction with subsequent degeneration as in the mutant strain (ZRDCT/Ch).

In the anophthalmic mouse, geniculate neurons establish contact normally with area 17 of the neocortex. ${ }^{46}$ Striate cortical efferents to lateral geniculate nucleus ${ }^{47}$ and superior colliculus, ${ }^{47}$ with increased connections to posterior thalamus, ${ }^{42}$ are also established. These connections may ensure the survival of lateral geniculate neurons, in contrast to their degeneration following postnatal eye enucleation. ${ }^{45}$

In adult human beings, monocular enucleation causes anterograde transneuronal degeneration in the lateral geniculate nucleus ${ }^{48.49}$; but the changes in striate cortex are less impressive. ${ }^{50,51}$ Our findings in this case of bilateral anophthalmia are analogous. Apparently the visual cortex can still survive, develop, and organize cell layers in the absence of a retinogeniculate pathway. Nevertheless, judging from the depletion of neurons in the geniculate body, the geniculocortical pathway was seriously disrupted. This conclusion was supported by the evidence obtained using the cytochrome oxidase stain. The patches of stronger cytochrome oxidase activity present in normal monkeys ${ }^{5,52}$ and human beings were lacking. ${ }^{.1}$ In the macaque monkey, these patches receive a direct projection in layers II and III from the lateral geniculate body. ${ }^{52.54}$ Following eye removal in the macaque monkey, the patches innervated by geniculate laminae, corresponding to the missing eye, turn pale and shrink. ${ }^{5}$ In view of the appearance of the geniculate body (Fig 6), it was not surprising that the patches were absent altogether in this case. Finally, connections within striate cortex were also probably abnormal, since the dense tangential fiber plexus in layer IVb was extremely faint.

Our findings can be compared with those in three reports in the English literature that included gross and microscopic descriptions of all parts of the visual system. ${ }^{1.3}$ All three cases were characterized by complete absence of eye tissue, optic nerves, chiasm, and tracts. The lateral geniculate nuclei were not found in one case $^{1}$ and were small and nonlaminated in the other two. ${ }^{2.3}$ In one case, the calcarine cortex was normal grossly with normal cellular lamination, save for absence of the myelinated line of Gennari. ${ }^{2}$ The other two had small striate areas, one with ${ }^{1}$ and one without ${ }^{3}$ a line of Gennari, the latter case showing grossly malformed calcarine fissures.

It is possible that this patient's growth retardation is due to a single gene defect that affects the development of multiple areas, including the hypothalamus and the eye. A multivariate analysis of the pleiotropic effects caused by WhWh (anophthalmic white) in the Syrian hamster showed a high correlation with six hypothalamically mediated indicators. ${ }^{55}$ They included growth retardation, thyroid dysfunction, adrenal atrophy, and sterility, all findings that were present in this patient. Studies of some anophthalmic mice revealed pathologic changes in the hypothalamus, including alterations of the suprachiasmatic nuclei that were deprived of normal retinal afferents. ${ }^{56}$ Rats that are blinded or deprived of visual stimulation show growth retardation, ${ }^{57}$ delayed puberty, ${ }^{58}$ and reduced pituitary stores of growth hormone. ${ }^{57}$ Although this suggests an interdependence of hypothalamic and visual function, no histologic hypothalamic alterations were recognized in this case. Serial sections of the hypothalamus were not done, and in the absence of an optic chiasm, the suprachiasmatic nucleus could not be reliably identified. ${ }^{9}$
Russell Kerschmann, MD, performed the nonneurophthalmologic portion of the autopsy.

\section{References}

1. Recordon E, Griffiths GM: A case of primary bilateral anophthalmia (clinical and histological report). Br J Ophthalmol 1938;22:353-360.

2. Duckworth T, Cooper ERA: A study of anophthalmia in an adult. Acta Anat 1966;63:509522.

3. Haberland C, Perou M: Primary bilateral anophthalmia. J Neuropathol Exp Neurol 1969; 28:337-351.

4. Hoefnagel D, Keenan ME, Allen FH: Heredofamilial bilateral anophthalmia. Arch Ophthalmol 1963;69:760-764.

5. Horton JC, Hubel DH: Regular patchy distribution of cytochrome oxidase staining in primary visual cortex of macaque monkey. Nature 1981;292:762-764.

6. Lycosthenes: Prodigiorum al ostentorum chronicon. Basel, 1557.

7. Bartholin T: Historiarum anatomicarum rariorum. Centuria III. Observatio 47. Amsterdam, 1657.

8. Sorsby A: Anophthalmos: An unpublished manuscript by Briggs $J$ giving the first account of the familial occurrence of the condition. $B r J$ Ophthalmol 1934;18:469-472.

9. Treacher-Collins E: On anophthalmos. $R$ Lond Ophthalmol Hosp Rep 1887;11:429455.

10. Mann I: Developmental Abnormalities of the Eye, ed 2. Hagerstown, Md, Harper \& Row Publishers Inc, 1957, pp 60-66.

11. Duke-Elder S (ed): System of Ophthalmology. St Louis, CV Mosby Co, 1963, vol 3, pt 2: Anophthalmos and Extreme Microphthalmos, pp 416-429.

12. Pritikin RI: The rarity of true congenital bilateral anophthalmos. Metabol Pediatr Ophthalmol 1980;4:165-167.

13. Hodes BL, Snyder M: Ultrasonic diagnosis of congenital anophthalmos. J Pediatr Ophthalmol Strabismus 1978;15:107-108.

14. Michaels DD, Zugsmith GS: Bilateral anophthalmos and unilateral microphthalmos in siblings. Am J Ophthalmol 1963;55:1256-1259.

15. Bianchine JW: A family with microphthalmia, anophthalmia and concomitant oligophrenia. Birth Defects 1971;7(pt 8):205-206.

16. Pearce WG, Nigam S, Rootman J: Primary anoph thalmos: Histological and genetic features. Can J Ophthalmol 1974;9:141-145.

17. Roberts JAF: Sex-linked microphthalmia sometimes associated with mental deficiency. $\mathrm{Br}$ Med $J$ 1937;2:1213-1216.

18. Joseph R: A pedigree of anophthalmos. $\mathrm{Br}$ $J$ Ophthalmol 1957:41:541-543.

19. Sjogren T, Larsson T: Microphthalmos and anophthalmos with or without coincident oligophrenia. Acta Psychiatr Neurol, 1949, suppl 56, pp 1-102.

20. Lenz W: Recessiv-geschlechtsgebundene Mikrophthalmie mit multiplen Missbildungen. $Z$ Kinderheilkd 1955;77:384-390.

21. Hermann J, Opitz JM: The Lenz microphthalmia syndrome. Birth Defects 1969;5(pt 2):138143.

22. Goldberg MF, McKusick VA: X-linked colobomatous microphthalmos and other congenital anomalies: A disorder resembling Lenz's dysmorphogenetic syndrome. Am J Ophthalmol 1971;71:1128-1133.

23. Margolis S, Martin L: Anophthalmia in an infant of parents using LSD. Ann Ophthalmol 1980;12:1379-1381.

24. Pabst W: Thalidomide and congenital abnormalities of the eye. Ber Dtsch Ophthalmol Ges 1964:65:209-215.

25. Golden SM, Perman KI: Bilateral clinical anophthalmia: Drugs as potential factors. South Med $J$ 1980;73:1404-1407.

26. Frenkel LD, Keys MP, Hefferen SJ, et al: 
Unusual eye abnormalities associated with congenital cytomegalovirus infection. Pediatrics 1980;66:763-766.

27. Sarma V: Maternal vitamin A deficiency and fetal microcephaly and anophthalmia. Obstet Gynecol 1959;13:299-301.

28. Achelis E: Anophthalmus als Folge eines Interruptionversuches? Med Klin 1950;45:12141215.

29. Donoghue WM, Harvey J: A case of clinical anophthalmia with an abnormal karyotype. $J$ Ment Defic Res 1976;20:89-93.

30. Masket S, Galioto FM, Best M: Anophthalmia, multiple abnormalities and unusual karyotype. Am J Ophthalmol 1970;70:381-383.

31. Chang P, Perciaccante R, Miller OJ, et al: Anophthalmia and other anomalies associated with a ring chromosome No. 17-18. Cytologia 1975;40:135-140.

32. Patau K, Smith DW, Therman E, et al: Multiple congenital anomaly caused by an extra autosome. Lancet 1960;1:790-793.

33. Welter DA, Lawson LW, Scharff L, et al: Kleinefelter's syndrome with anophthalmos. $A m$ $J$ Ophthalmol 1974;77:895-898.

34. Ide $\mathrm{CH}$, Wollschlaeger $\mathrm{PB}$, Wollschlaeger $\mathrm{G}$ : Oculovertebral syndrome associated with cardiovascular abnormalities. Ann Ophthalmol 1972;4:836-841.

35. Majeski JA: Asplenia associated with congenital diaphragmatic defect and neurologic anomalies. South Med $J$ 1978;71:1447-1448.

36. Sassani JW, Yanoff M: Anophthalmos in an infant with multiple congenital anomalies. Am J Ophthalmol 1977;83:43-48.

37. Chase HB, Chase EB: Studies on an anophthalmic strain of mice and embryology of the eye region. J Morphol 1941;68:279-301.

38. Leonard A: Hereditary anophthalmia in the progeny of an X-irradiated female rat. Jikken Dobutsu 1977;26:255-257.

39. Leung CCK, Hung $\mathrm{CH}$, Hudson $\mathrm{BG}$, et al:
Congenital abnormalities induced by heterologous antisera directed against rat kidney glycoproteins isolated by concanavalin A affinity chromatography. Pediatr Res 1979;13:1211-1216.

40. Hoff J, Winestock D, Hoyt WF: Giant suprasellar aneurysm associated with optic stalk agenesis and unilateral anophthalmos. $J$ Neurosury 1975;43:495-498.

41. Bachman DS, Kosnik EJ, Boesel CP, et al Congenital anophthalmia associated with intracranial germinoma. Dev Med Child Neurol 1980;22:778-781.

42. Paterson JA, Kaiserman-Abramof IR: The oculomotor nucleus and extraocular muscles in a mutant anophthalmic mouse. Anat Rec 1981; 200:239-251.

43. Harch C, Chase HB, Gonsalves NI: Studies on an anophthalmic strain of mice: VI. Lens and cup interaction. Dev Biol 1978;63:352-357.

44. Kennedy RE: The effect of early enucleation on the orbit in animals and humans. $A m J$ Ophthalmol 1956;60:277-306.

45. Cullen MJ, Kaiserman-Abramof IR: Cytological organization of the dorsal lateral geniculate nuclei in mutant anophthalmic and postnatally enucleated mice. $J$ Neurocytol 1976;5:407424 .

46. Kaiserman-Abramof IR, Graybiel AM, Nauta WJH: The thalamic projection to cortical area 17 in a congenitally anophthalmic mouse strain. Neuroscience 1980;5:41-52.

47. Kaiserman-Abramof IR, Graybiel AM, Nauta WJH: Neural connections of area 17 in an anophthalmic mouse strain, abstracted. Neuroscience $1975 ; 1: 102$

48. Le Gros Clark WE: A morphological study of the lateral geniculate body. $B \cdot J$ Ophthalmol 1932;16:264-284.

49. Goldby F: A note on transneuronal atrophy in the human lateral geniculate body. $J$ Neurol Neurosurg Psychiatry 1957;20:202-207.

50. Haseltine EC, DeBruyn EJ, Casagrande
VA: Demonstration of ocular dominance columns in Nissl-stained sections of monkey visual cortex following enucleation. Brain Res 1979;176:153158 .

51. Horton JC, Hedley-Whyte ET: Mapping of cytochrome oxidase patches and ocular dominance columns in human visual cortex. Philos Trans $R$ Soc Lond Biol, in press.

52. Hendrickson AE, Hunt SP, Wu JY: Immunocytochemical localization of glutamic acid decarboxylase in monkey striate cortex. Nature 1981;292:605-607.

53. Fitzpatrick D, Itoh K, Diamond IT: The laminar organization of the lateral geniculate body and the striate cortex in the squirrel monkey (Saimiri sciureus). J Neurosci 1983;3:673702.

54. Horton JC: Cytochrome oxidase patches: A new cytoarchitectonic feature of monkey visual cortex. Philos Trans $R$ Soc Lond Biol, in press.

55. Asher JH: Concerning the primary defect leading to the pleiotropic effects caused by anophthalmic white (Wh) in the Syrian hamster Mesocricetus auratus. $J$ Exp Zool 1981;217:159169.

56. Silver J: Abnormal development of the suprachiasmatic nuclei of the hypothalamus in a strain of genetically anophthalmic mice. J Comp Nomol 1977;176:589-606.

57. Sorrentino S, Reiter RJ, Schalch DS: Pineal regulation of growth hormone synthesis and release in blinded and blinded-anosmic male rats. Neuroendocrinology 1971;7:210-218.

58. Osman P, Welschen RW, Moll J: Antigonadotropic and anti-growth effects of the pineal in immature female rats. Neuroendocrinology 1972;10:121-128.

59. Lydic R, Schoene WC, Czeisler CA, et al: Suprachiasmatic region of the human hypothalamus: Homolog to the primate circadian pacemaker? Sleep 1980;2:355-361. 